\title{
A CONCEPÇÃo NEOFREgIANA DE PROPOSIÇÃo EM MENTE E Mundo, DE J. McDowell
}

\author{
José Renato Salatiel ${ }^{1}$
}

Resumo: A epistemologia tradicional trata de certas questōes, como a justificação de crenças empíricas, em um viés cartesiano representacionalista, o qual distingue conceitos e experiência em diferentes domínios metafísicos. Mas, desse modo, torna-se difícil explicar como a percepção pode ter um papel normativo no processo de justificação do nosso conhecimento sobre o mundo. A soluçáo recomendada por McDowell, em Mente e Mundo, é considerar que a percepçáo envolve capacidades conceituais e que ela provê um acesso direto aos objetos da realidade externa. Além disso, McDowell endossa a teoria proposicional neofregiana de Evans, que, em parte, explica como o conteúdo da experiência pode ser estruturado, de sorte a atender ao empirismo mínimo. O presente artigo objetiva analisar as implicaçóes da semântica neofregiana de McDowell para o projeto filosófico delineado em Mente e Mundo. Argumenta-se que essa conexáo entre a teoria conceitualista da percepção e a teoria semântica dos sentidos de re suporta o disjuntivismo epistemológico, que visa a escapar ao problema cético.

Palavras-chave: Pensamento singular. Percepção. John McDowell. Frege.

\section{INTRODUÇÃo}

Uma questão central da epistemologia concerne à justificação de crenças empíricas e, em específico, ao papel da percepção nesse processo de avalizar nosso conhecimento proposicional sobre o mundo. A representação de estado de coisas em proposiçóes que dizem algo de verdadeiro, ao invés de falso, por sua vez, requer uma investigação semântica sobre a referência e os termos singulares. Mente e Mundo, de John McDowell, tem a virtude de alinhavar esses dois domínios filosóficos - conhecimento e linguagem - de um modo original, dentro de diferentes tradiçốes do pensamento ocidental.

${ }^{1}$ Professor adjunto do Departamento de Filosofia da Universidade Federal do Espírito Santo (UFES). Vitória, Espírito Santo, Brasil.

(D) https://orcid.org/0000-0001-5858-1248. E-mail: jose.salatiel@ufes.br.

http://dx.doi.org/10.1590/0101-3173.2020.v43n4.14.p231 
A tese epistemológica central da obra é a de que a percepção é uma atividade cognitiva que ocorre dentro da esfera da racionalidade. Assim, o conteúdo sensório da experiência é conceitualmente estruturado, de forma a permitir a chancela de juízos empíricos. A tese conceitualista é amparada, por seu turno, por uma teoria do sentido de re, apresentada apenas em linhas gerais, ao longo das conferências que compóem o livro.

O objetivo deste artigo é explicitar a conexão entre essas duas teorias, em Mente e Mundo, conexão essa que não parece clara, dada a complexidade da obra. Argumentarei que há uma dependência entre a tese conceitualista da percepção, a concepção semântica neofregiana de pensamento singular e a doutrina disjuntivista proposta pelo filósofo, as quais, em conjunto, oferecem uma dissolução das objeções céticas ao conhecimento empírico. Para desenvolver este trabalho, recorrerei, além da referida obra, a textos anteriores de McDowell, em específico um conjunto de artigos reunidos em Meaning, Knowledge, and Reality (1998).

No que segue, adoto como estratégia teórica a exposição da crítica de McDowell a dois argumentos semântico-epistêmicos, elaborados por Donald Davidson (1986) e Tyler Burge (1977), que sustentariam, segundo o filósofo sul-africano, uma noção cartesiana de experiência. Para McDowell, essa abordagem tradicional deveria ser suplantada pela doutrina que ele chama de empirismo mínimo.

$\mathrm{O}$ artigo divide-se em quatro partes. A primeira seção tem o propósito de caracterizar o problema da percepção na justificação de crenças, cujas respostas tendem ora para o aceno ao "mito do dado", ora às vertentes coerentistas. McDowell propóe "curar" essa "angústia”, mediante o entendimento das faculdades perceptivas como exercícios de nossas capacidades conceituais.

A segunda seção expóe uma segunda problemática, sobre o pensamento demonstrativo, e as tentativas de sua resolução em dois tipos de teorias proposicionais: dependentes do objeto (proposiçóes russelianas) e independentes do objeto (sentidos fregianos). A partir desse aparato teórico, é discutida, na seção três, a crítica de $\mathrm{McD}$ owell às modalidades de dicto e de re em Burge e, na quarta, é focalizado seu endosso à teoria do sentido de re fregiano de Evans (1982). Concluo o trabalho, analisando possíveis implicações epistêmicas dessa articulação teórica para uma concepção disjuntivista da experiência. 


\section{A tese conceitualista}

Mente e Mundo versa sobre essa supracitada relação em um viés privilegiadamente epistemológico, mas não somente. $\mathrm{Na}$ obra, McDowell retoma a máxima kantiana de que "pensamentos sem intuições são vazios, e intuiçóes sem conceitos são cegas” (CRP A51/ B75), para reivindicar uma posição cuja finalidade é dupla. De um lado, suprir a necessidade de se exortar os dados dos sentidos, sobre os quais não se tem nenhum acesso normativo, como conteúdo legítimo de crenças. De outro, evitar que o pensamento não responda a nada além do âmbito de suas próprias inferências.

Contra essa oscilação, ele sustenta a tese de que os exercícios das capacidades conceituais não se restringem a uma fronteira da experiência são, conforme afirma, indelimitados (unboundedness) -, e assim, as entregas da experiência (percepção) já seriam envoltas em um repositório conceitual (McDOWELL, 2005, p. 71-72).

A natureza do conhecimento humano é caracterizada por um contexto normativo da experiência, naquilo que Sellars chamou de "espaço lógico das razôes", no qual o domínio competente de articulações linguísticas é distintivo, para que haja a justificação de um saber empírico. Desse modo, afirma Sellars, quando um sujeito $S$ diz que vê que "F é G", ele não estaria apenas descrevendo uma impressão sensorial a partir de uma observação, mas endossando um certo conteúdo proposicional, ou seja, fazendo um juízo a respeito da experiência. "Caracterizar as experiências de $S$ como um ver é o mesmo que [...] aplicar o conceito semântico de verdade a tais experiências" (SELLARS, 2008, p. 47).

A experiência sensorial, pelo contrário, é despojada de elementos racionais. Portanto, ela não pode ser fonte de legitimação de juízos empíricos. Segundo Sellars, o análogo à "falácia naturalista" (SELLARS, 2008, p. 28), cometido pelo chamado "mito do dado", consiste em caracterizar um determinado estado ou episódio interno como sendo saber, uma vez que isso significa situá-lo "[...] no espaço lógico das razōes, do justificar e ser capaz de justificar o que se diz" (SELLARS, 2008, p. 51). Em outras palavras, a habilidade de atestar um determinado conteúdo proposicional envolve um processo de aprendizagem de conceitos, ao passo que isso não ocorre ao se sentir um determinado conteúdo sensorial

O problema é explicar como a percepção, sendo uma atividade passiva de recebimento de estímulos sensórios do ambiente, pode adentrar ao domínio 
da espontaneidade, para usar um termo kantiano. Afinal, é somente mediante faculdades perceptivas que se estabelece contato com o mundo.

Davidson, assim como Sellars, critica o mesmo pressuposto de que crença e percepção compartilham o mesmo conteúdo epistêmico, entendimento esse que subjaz às teorias fundacionistas ${ }^{2}$. "A relação entre uma sensação e uma crença não pode ser lógica, uma vez que sensaçóes não são crenças ou outras atitudes proposicionais" (DAVIDSON, 1986, p. 311). A única dependência que uma crença possui em relação à percepção, ressalta, é do tipo causal - estados perceptivos seriam, no máximo, a causa de atitudes proposicionais, nunca a justificativa para elas (DAVIDSON, 1986, p. 311312). O argumento de Davidson pode, então, assim ser formulado:

i. A justificação para crenças empíricas somente pode ocorrer com base em estados cujo conteúdo é conceitual (proposiçóes).

ii. Experiência perceptual é um estado destituído de conteúdo conceitual.

iii. Portanto, a experiência perceptual não pode servir de base justificatória para crenças empíricas.

"Todas as crenças", conclui Davidson, "são justificadas neste sentido: elas são apoiadas por numerosas outras crenças [...] e possuem um pressuposto em favor de sua verdade" (DAVIDSON, 1986, p. 319). Podemos ter algumas crenças falsas, mas não todas, e é com base na coerência com esse conjunto de crenças que podemos justificar a crença $y$ de que uma crença $x$ é verdadeira. Apenas crenças, por conseguinte, podem servir de base justificatória para outras, não se podendo apelar a nenhuma instância legisladora que esteja fora do "espaço lógico das razōes".

McDowell ratifica a rejeição da noção empirista de dados dos sentidos - ou outros tipos de crenças com estatuto de serem básicas - de Davidson e Sellars. Mas, em sua interpretação, a posição coerentista à qual essa rejeição leva, ao menos em Davidson, é insatisfatória, na medida em que, sem controle externo, promove "clausura na esfera do pensamento" (McDOWELL, 2005 , p. 52), a qual opera como "um giro sem atrito ocorrendo no vazio"

2 Teorias fundacionistas sustentam, grosso modo, que ter um conteúdo mental (de natureza não inferencial) confere ao sujeito uma justificação prima facie para uma crença qualquer. 
(McDOWELL, 2005, p. 47). Isso, por sua vez, expóe o conhecimento ao ceticismo ${ }^{3}$ e torna atraente, mais uma vez, o apelo ao dado.

O maior problema na análise de Sellars e Davidson, contudo (e ainda que estejam certos sobre o empirismo clássico), é que essa posição, segundo McDowell, mantém um "abismo" (gap) entre a realidade externa e o domínio conceitual. Para ele, essa perspectiva é equivocada, pois pressupóe uma fronteira externa ao conceitual. Isso deixaria o "mundo" para além do escopo da responsabilidade do sujeito, o qual, no entanto, o requer para justificar crenças empíricas que, no máximo, lhe ofereceriam apenas desculpas (McDOWELL, 2005, p. 44 e 49). É essa divisão que provocaria uma oscilação entre, de um lado, o apelo ao "mito do dado" e, de outro, abordagens coerentistas que não resistiriam aos questionamentos céticos.

A proposta de um empirismo mínimo é que "a ideia de um direcionamento ao mundo empírico só é inteligível em termos de responsabilidade perante o tribunal da experiência, concebido em termos de um mundo que impressiona sujeitos percipientes" (McDOWELL, 2005, p. 28; cf. p. 29-30). A experiência para McDowell, assim, é mais do que mera causalidade: ela tem um papel importante como "tribunal".

Por isso, ele precisa rejeitar a segunda premissa do argumento acima formulado. A tese conceitualista de McDowell é que os conteúdos representacionais são completamente conceitualizados, ou seja, a experiência não pode ser concebida fora do espaço lógico das razões (McDOWELL, 2005, p. 46). Os conceitos não agem sobre as entregas da receptividade, mas a própria percepçáo já é, ela mesma, conceitualizada, embora, em parte, sejamos passíveis em relação àquilo que experienciamos. Assevera McDOWELL (2005, p. 49):

As capacidades conceituais que são passivamente postas em jogo na experiência pertencem a uma rede de capacidades envolvidas no pensamento ativo, rede esta que governa racionalmente a produçáo de respostas que, na busca de compreensão, vamos dando aos impactos do mundo sobre a nossa sensibilidade.

Em suma, o "espaço lógico de razóes" não ocorre dentro de uma fronteira que o separa da realidade externa. Quando um sujeito vê um

\footnotetext{
3 Assinala McDowell: “[...] nada, no quadro que nos é oferecido por Davidson, impediria alguém de ser um cérebro posto na cuba de um cientista maluco” (2005, p. 53).
} 
objeto com determinadas propriedades, ele já deve estar "equipado" com os conceitos adequados para o estado cognitivo de ver que tal coisa é de tal modo (McDOWELL, 2005, p. 67). As capacidades receptivas (percepção) ocorrem dentro da esfera do conceitual, em um conteúdo linguisticamente articulado ${ }^{4}$. O ato de pensar, exercício da espontaneidade, é um juízo que se faz sobre isso ("Os juízos apenas endossam um conteúdo já conceitualizado" [McDOWELL, 2005, p. 85]), e é sobre esse juízo que a realidade imporá constrangimentos, ou seja, atuará como "tribunal". Por isso, ele enfatiza: "A coerção vem de fora do pensar, mas não de fora daquilo que é pensável” (McDOWELL, 2005, p. 66).

A essa tensão criada pelo dado como acesso cognitivo ao mundo subjaz uma outra, segundo McDowell, ocasionada por uma concepção equivocada de proposição, do tipo russeliana ${ }^{5}$, segundo a qual a proposição deve figurar o dado para que ocorra o juízo. A seguir, analisarei essa contraparte semântica da oscilação que é divisada tenuamente em Mente e Mundo, porém, que, apesar disso, é fundamental para entender a noção de conteúdo conceitual ali defendida. Começarei expondo as questôes envolvendo o pensamento singular e, a seguir, a posição de $\mathrm{McD}$ owell a respeito de proposições neofregianas.

\section{O PROBLEMA DO PENSAMENTO SINGULAR}

Entender as questôes envolvendo o pensamento empírico, ou seja, aquele estado mental que se dirige ao mundo, requer a análise de proposições com termos singulares, cujas condiçóes de verdade dependem de fatos que são por elas denotados. Um tipo particular de pensamento singular, aquele baseado na percepção, é expresso em proposiçôes contendo pronomes demonstrativos, como, por exemplo:

\footnotetext{
${ }^{4}$ Não é, portanto, como se a espontaneidade atuasse sobre a experiência, fazendo com que juízos perceptuais convertessem um conteúdo nấo conceitual em conteúdo conceitual (modelo de EVANS, 1982). Mas é a própria experiência que deve ser entendida como resultado do exercício de nossas capacidades conceituais. McDowell explica melhor essa proposta, com seu conceito de segunda natureza (cf. "Quarta Conferência", em Mente e Mundo). Segundo ele, a aquisição de linguagem e de compromissos epistêmicos, isto é, o adentrar no "espaço lógico das razóes", seria uma realização de nossas potencialidades animais, incluindo nosso amadurecimento intelectual.

5 O adjetivo "russeliana” aqui é uma referência, como veremos na próxima seção, a uma noção de proposiçấo defendida por Russell.
} 
"Esta xícara de café é branca”.

A condição de verdade dessa sentença (1) depende da percepção de uma xícara de café à qual se possa atribuir a propriedade de ser branca. Contudo, além de um elemento denotativo expresso no termo singular da sentença, há um componente intencional dado pelo conteúdo mental ou atitude proposicional dirigida ao objeto. Nesse caso, dizemos que há, em suma, duas perspectivas de análise de proposiçōes: dependentes do objeto (object dependent) e independentes do objeto (object independent). ${ }^{6}$

$\mathrm{Na}$ segunda perspectiva, independente do objeto, a proposição expressaria um pensamento singular, mesmo que a xícara de café não existisse, e o sujeito, nesse caso, estaria diante de uma xícara ilusória ou sofrendo de alucinação. As dificuldades epistêmicas aqui são claras, pois não haveria como responder ao ceticismo em relaçáo à crença do sujeito, a qual permaneceria inalterada em uma situação na qual a xícara fosse substituída por uma cópia. Na primeira perspectiva, dependente do objeto, não há essa possibilidade: caso não haja nenhum objeto referido, não há nenhum conteúdo demonstrativo do pensamento e, assim, o sujeito teria apenas a ilusão de um pensamento empírico.

A interpretação-padrão concebe a perspectiva dependente do objeto como sendo russeliana, e a independente do objeto, como fregiana. A originalidade da interpretação de $\mathrm{McD}$ owell consiste na tese de que proposiçóes (neo)fregianas são dependentes do objeto, ainda que se diferenciem de proposiçóes russelianas ${ }^{7}$. Examinarei, nesta seção, o panorama clássico dessas teorias, em Frege e Russell.

Na semântica fregiana, a partir da publicação de "Sobre o sentido e a referência” (1892), ${ }^{8}$ há dois níveis de análise de uma proposição, o do sentido (Sinn) e o da referência (Bedeutung), introduzida para lidar com o problema de enunciados identitários. Considere agora a seguinte sentença:

${ }^{6}$ Recentemente, Crawford (2018) apresentou a tese de uma teoria dependente de propriedade (property-dependent theory), na qual o conteúdo demonstrativo do pensamento depende não de objetos, mas de suas propriedades observadas.

${ }^{7}$ A teoria das proposiçôes neofregianas de re deve ser creditada também a Evans (1982), que omito intencionalmente, neste artigo, em razão de seu recorte temático. Sobre a contribuição de Evans, cf. Salatiel (2019).

${ }^{8}$ Desconsideraremos aqui, em razão dos propósitos do trabalho, a fase anterior do pensamento de Frege, marcadamente a de Begriffsschrift (1879) e Fundamentos da Aritmética (1884), na qual ele sustenta uma posição independente do objeto. Para uma comparação de ambas as fases, cf. Geirsson (2002). 
"A xícara de café de João é branca".

Assumindo que os termos singulares "esta xícara de café" (1) e "a xícara de café de João" (2) se referem ao mesmo objeto, isto é, possuem a mesma referência (Bedeutung), ambas as sentenças possuem o mesmo valor semântico. No entanto, as sentenças (1) e (2) têm sentido (Sinn) ou valores cognitivos, diferentes, pois um sujeito pode entender ambas e ter diferentes atitudes proposicionais em relação a elas, segundo o critério de Evans (EVANS, 1982, p. 18-19). O sujeito pode, por exemplo, não saber que ambas as xícaras se referem ao mesmo objeto e, assim, crer que a primeira sentença é verdadeira e a segunda, falsa.

Frege conceitua sentido, de modo geral, como a forma de apresentação do objeto (FREGE, 2009, p. 130-131). Por objeto ele compreende aquilo que é designado por um nome, ao qual se pode aplicar um predicado. Já por nome, em específico nome próprio, ele entende uma classe ampla de expressóes saturadas, as quais incluem demonstrativos e descriçóes definidas.

O objeto em questão, a xícara, é apresentado de duas maneiras diferentes, ora usando um demonstrativo ("esta xícara de café”), ora por meio de uma descrição definida ("a xícara de café de João"). Uma analogia disso é como percebemos visualmente um objeto de diferentes perspectivas, em função do ponto de observação, resultando em representaçóes visuais diversas do mesmo objeto.

Outro ponto importante nessa doutrina é que o sentido determina, em parte, a referência do objeto, "[...] de tal modo que ao sinal [a palavra] corresponde um sentido determinado e ao sentido, por sua vez, corresponde uma referência determinada" (FREGE, 2009, p. 132). Entretanto, destaca Frege, "[...] apreender um sentido nunca assegura a existência de sua referência" (p. 133). No caso de nomes vazios, como "Pégaso" ou "o ponto mais distante do universo", temos proposiçóes sem referência, mas com sentido, pois um sujeito pode ter atitudes proposicionais, como uma crença, a respeito dessas sentenças que contenham nomes próprios (termos singulares). O problema é que tais sentenças contendo nomes vazios não seriam, assim, nem verdadeiras e nem falsas, violando o Princípio do Terceiro Excluído. Evita-se essa conclusão, indesejável para a lógica clássica, admitindo-as como uma espécie de classe 
"degenerada" de sentidos: sentidos ou pensamentos aparentes (Scheingedanken) (PW, p. 130, 1897). ${ }^{9}$

Sentenças que nada denotam podem, ainda, expressar proposiçóes com sentido. E, se assim o fazem, essas proposiçôes devem ser independentes do objeto. Frege afirma:

Nomes próprios designam objetos, e um pensamento singular é sobre objetos. Mas não podemos dizer que um objeto é parte de um pensamento como um nome próprio é parte da sentença correspondente. Mont Blanc com suas massas de neves e gelo não é parte do pensamento de que Mont Blanc possui mais de 4.000 metros de altura [...] (PW, p. 187, 1906; cf. $P M C$, p. 63, 1904).

O nome designa um objeto e é, ele próprio, parte de uma sentença que expressa um pensamento singular. Contudo, o pensamento singular que contém o nome, por si só, não garante que o objeto seja apreendido como existente, porque uma sentença assertórica pode ser enunciada em um contexto ficcional ou poético, diferentemente de um contexto discursivo científico, no qual os falantes almejam o conhecimento e a verdade (FREGE, 2009, p. 138). Como consequência epistêmica, pode haver um pensamento singular, mesmo que o objeto seja uma ilusão ou uma alucinação do sujeito.

Essa doutrina fregiana dos sentidos, contudo, não é amplamente aceita entre filósofos. Muitos preferem uma abordagem russeliana ${ }^{10}$, que rejeita o conceito fregiano de sentido (Sinn) em sua análise. Para Russell, numa proposição singular, um nome se refere a um indivíduo que satisfaz a predicação a ele atribuída, caso no qual a proposição é verdadeira e, caso contrário, falsa. Mas, se o indivíduo não existe, a proposição é sem sentido. "Sempre que o sujeito gramatical de uma proposição puder presumivelmente não existir, sem que isso torne a proposição sem sentido, será claro que o sujeito gramatical não é um nome próprio" (WHITEHEAD; RUSSELL, 1910, p. 69). ${ }^{11}$

9 Evans defende essa leitura de Frege a respeito de pensamentos aparentes (mock thoughts) (EVANS, 1983, p. 28-30; SALATIEL, 2019), ratificada por McDowell (2009, p. 183 e p. 184, n. 41). Para uma crítica a essa interpretação, ver BELL, 2005, p. 75.

${ }^{10}$ Russell elaborou diferentes teorias proposicionais. O período da presente análise vai de 1905 a 1918 , sobretudo dos textos "Da denotaçâa" (1905) (RUSSELL, 1989a), "Conhecimento por familiaridade e descrição" (1917) (Idem, 1977), e "Filosofia do atomismo lógico" (1918) (Idem, 1989b).

${ }^{11}$ Russell assevera (1977, p. 235-236): "Todas as proposiçōes que nos são inteligíveis, quer se refiram ou não, primordialmente, a coisas que só nos são conhecidas por descrição, são compostas totalmente 
No caso de sentenças que contenham nomes próprios, como "Pégasus" ou "Papai Noel”, por exemplo, ele frisa que não se trata de nomes genuínos, mas de abreviaçôes de descrições definidas. Em descriçôes definidas, a forma lógica é uma sentença quantificada complexa, na qual não figura um termo singular (RUSSELL, 1989a). Assim, os enunciados, nesse caso, serão significativos, exista ou não um indivíduo que atenda à denotação.

As únicas expressões singulares genuínas, sustenta ele, são locuções demonstrativas, como "este", "aquele”, "eu” e "agora”, que apontam para um objeto existente (RUSSELL, 1989b, p. 72; cf. 1977, p. 229). Assim, "Esta xícara de café é branca" (1) contém o objeto ao qual a sentença se refere, enquanto "A xícara de João é branca" (2) é uma descrição definida que não requer o objeto denotado para fazer sentido.

Há, por conseguinte, em sentenças com termos singulares, uma dependência do objeto: caso ele não exista, não pode haver um pensamento. É uma perspectiva cartesiana, na qual o sujeito não pode se enganar sobre os próprios pensamentos (se o referente for ilusório). Somente pode haver pensamento singular, quando em contato direto com estados privados, sejam eles dados dos sentidos, sejam oriundos da percepção de objetos, memória ou outros conteúdos mentais. Esse seria um tipo de conhecimento mais básico, que Russell (1977) chama de conhecimento por familiaridade, em oposição ao conhecimento por descrição.

Porém, para McDowell, a perspectiva russeliana dependente do objeto não é aceitável, uma vez que mantém a mesma tensão entre, de um lado, conceitos (propriedades), domínio das crenças e valores ("espaço lógico das razóes"), e, de outro, objetos extralinguísticos, denotados ou referidos por sentenças, domínio da percepção e da causalidade. Além disso, em uma relação imediata e direta com o objeto, mediante a percepção, apela-se ao "mito do dado" (dados dos sentidos). A ideia, mais uma vez, é de que há um interno/ sujeito e um externo/objeto do qual o sentido/conceito seria um intermediário ou mediador, localizado na "fronteira" entre ambos.

A diferença entre as abordagens russeliana e fregiana é que, na primeira, uma proposição contém, além do predicado (conceito), um objeto ao qual ela se refere, enquanto, segundo Frege, um pensamento (Gedanke) é apenas sentido, inteiramente conceitualizado, podendo ser entendido como

de constituintes com que estamos familiarizados, pois um constituinte com o qual não estamos familiarizados nos é ininteligível". 
conteúdos descritivos, mas não como uma referência direta (familiaridade). Uma posição intermediária consiste, conforme veremos, em adotar uma concepção de sentido de re.

\section{BURGE: DE RE/DE DICTO}

Para o projeto de McDowell, é importante rejeitar a abordagem neorrusseliana, na qual o pensamento singular contém tanto elementos conceituais quanto extraconceituais, conferidos pelos objetos do mundo. É justamente essa fronteira entre conceitual e náo conceitual que McDowell ataca. Contrária a essa perspectiva, ele adotará uma noção proposicional neofregiana de sentido de re. Isso será essencial para suportar sua tese, em Mente e Mundo, de que o conteúdo da percepção é completamente conceitualizado.

McDowell (1984) argumenta em favor de uma teoria proposicional fregiana que acomode, de modo coerente, pensamentos singulares. $\mathrm{O}$ problema é que, de acordo com a interpretação-padrão, sentidos fregianos são inteiramente conceitualizados, isto é, estados mentais internos codificados linguisticamente pelo repertório do sujeito e, como tais, não podem ser pensamentos singulares, os quais dependem de objetos externos (res).

Para responder a isso, a estratégia de McDowell consiste em rejeitar a tese, defendida por Tyler Burge (1977), de que pensamentos, sendo conceituais, são representaçôes mentais internas e, portanto, estão apartados do espaço externo dos objetos de referência.

O raciocínio elaborado por Burge baseia-se em uma distinção entre modalidades epistêmicas de dicto e de re, análoga àquela analisada por Quine, no caso de modalidades aléticas ${ }^{12}$. Considere-se como exemplo as seguintes sentenças:

João crê que alguém inventou a lógica.

Existe alguém que João crê ser o inventor da lógica.

\footnotetext{
${ }^{12}$ W. V. O. Quine usa análise similar, no contexto de sua crítica à ontologia da modalidade. Ele distingue expressōes de modalidade de dicto, ou seja, sobre o que é dito, de modalidade de re (sobre as coisas). No primeiro caso, temos a fórmulas " $\square \exists x A x$ ", cuja necessidade incide sobre uma proposição (Necessariamente "Existe algo que possui a propriedade A"). No segundo, a fórmula " $\exists \mathrm{x}$ ( $\square \mathrm{Ax}$ )", na qual a necessidade está sob escopo do quantificador existencial e, portanto, diz respeito aos indivíduos ("Existe algo que necessariamente possui a propriedade A"). Em linhas gerais, Quine emprega essa distinção para criticar modalidades ontológicas, que, para ele, nos comprometeria com uma forma de essencialismo (QUINE, 2011).
} 
Um modo de caracterizar a diferença entre ambas as sentenças é por um critério de extensionalidade (princípio de substitutividade). No caso de re (4), pode-se fazer as seguintes instanciações do termo referencial, substituindo o nome por uma descrição definida atinente ao mesmo indivíduo:

(4a) Aristóteles é a pessoa que João crê ser o inventor da lógica.

(4b) O discípulo de Platão é a pessoa que João crê ser o inventor da lógica.

Todavia, o mesmo não acontece ao se aplicar o mesmo princípio ao caso de dicto (1), pois João pode ter diferentes atitudes proposicionais em relação às sentenças "Aristóteles inventou a lógica" e "O discípulo de Platão inventou a lógica", alterando, assim, o valor de verdade da sentença (e, mesmo que ele saiba que se trata da mesma pessoa, o conteúdo da crença seria diferente).

Mas esse critério, argumenta Burge, não é adequado, porque ele pode falhar em casos que são, evidentemente, de re, como nos seguintes:

João crê que esta xícara de café é branca.

João crê que a xícara de Paulo é branca.

Apesar de João não saber que a xícara à qual ele se refere pertence a Paulo, a sentença claramente se refere diretamente a um objeto através de um demonstrativo ("esta") e, dessa maneira, o princípio de substitutividade falharia em apontar a diferença entre as modalidades (BURGE, 2007, p. 46). Burge não sugere um critério alternativo, contudo, apresenta o que seria uma forma mais clara de caracterizar a diferença, observando-se a forma lógica, de um ponto de vista semântico e outro epistêmico.

Dadas as respectivas formalizaçóes de (3) e (4), usando o operador de crença "B", a constante individual "a" e o predicado "P", obtêm-se as seguintes fórmulas: 


\section{$\mathrm{Ba} \exists \mathrm{xPx}$ $\exists \mathrm{xBaPx}$}

A distinção, logo, ficaria explícita: na fórmula (7), a modalidade epistêmica é de dicto, pois ela opera sobre uma fórmula quantificada ( $\exists \mathrm{xPx}$ ) ou uma proposiçáo completamente expressa. $\mathrm{Na}$ sentença (8), a modalidade epistêmica está sob o escopo do quantificador existencial ( $\exists \mathrm{xBaPx}$ ), operando, por consequência, sobre a predicação de uma entidade, no caso, um indivíduo particular (res) e uma - para usar um conceito russeliano - função proposicional (Px) (BURGE, 2007, p. 47). Em nível semântico, fica claro que temos, aqui, duas concepçóes proposicionais, uma fregiana e outra russeliana:

De forma geral, atribuiçôes puramente de dicto fazem referência a proposiçōes completas - entidades cuja verdade ou falsidade são determinadas sem apoio de uma aplicação ou interpretação em um contexto particular. Locuçôes de re dizem respeito a predicaçôes concebidas amplamente. Elas descrevem uma relação entre sentenças abertas (ou o que elas expressam) e objetos. (BURGE, 2007, p. 48, grifos do autor).

O correspondente epistêmico à expressão linguística é o conceito, concebido como uma representação de objetos no pensamento. Assim, em um nível epistêmico, uma atitude proposicional é de dicto, quando o conteúdo da crença é completamente conceitualizado, isto é, um conteúdo cognitivo inteiramente articulado linguisticamente. Numa atitude proposicional de re, ao contrário, o conteúdo da crença depende de elementos contextuais, como a existência de um indivíduo, o qual o sujeito acredita ter uma tal propriedade (BURGE, 2007, p. 51). É o caso, por exemplo, de uma crença perceptual:

Uma crença de re é uma crença cuja correta atribuição coloca o sujeito [believer] em uma relação não-conceitual e contextual apropriada com objetos aos quais a crença se refere [...]. Por exemplo, apesar de conceitos poderem inevitavelmente fazer parte da aquisição de crenças perceptuais, a relaçáo do sujeito com o objeto relevante não é meramente aquela que ele concebe ou, de outro modo, representa. Seus órgáos dos sentidos são afetados por ele (BURGE, 2007, p. 51).

Enquanto as condiçóes de verdade de uma crença de dicto são dadas pelo conteúdo conceitualizado (sentido), o qual estabelece as condiçóes que 
devem ser satisfeitas para a sentença ser verdadeira ou falsa, uma crença de re demandaria um mecanismo referencial, como o uso de demonstrativos ou índices. Por seu turno, a justificação de uma crença empírica, segue o argumento de Burge, requer uma experiência perceptual, e o resultado é uma crença de re (BURGE, 2007, p. 52-53). Essas seriam, sustenta ele, crenças mais básicas na aquisição do conhecimento: "Muitas de nossas crenças de dicto são justificadas porque são baseadas em rumores confiáveis de outros. Mas então, no mínimo, os 'outros' devem ter alguma crença de re para fundamentar sua autoridade a respeito do assunto" (BURGE, 2007, p. 53).

Já a perspectiva de Frege, assinala Burge, assume que: (a) todo pensamento ou crença representa um objeto de um determinado ponto de vista (modo de apresentaçáo); e (b) essa perspectiva conceitual determina completamente o objeto do conteúdo de nossas crenças. Esses dois princípios reduziriam crenças de re a crenças de dicto (o sentido determinaria o referente), contrariamente ao que Burge afirma, conforme visto no parágrafo anterior (BURGE, 2007, p. 57).

O problema, segundo ele, estaria em (b). Para Burge, a relação entre crenças de re e objetos náo pode ser puramente conceitual, mas é, sobretudo, contextual, como no caso das crenças perceptuais. Considere-se, logo, a seguinte sentença:

"Esta xícara branca contém châ" é igual a "Esta xícara branca contém châ".

O enunciado será tautológico, se denotar o mesmo objeto, mas informativo, se apontar para diferentes objetos. Nesse caso, o que determinará o objeto de referência do demonstrativo "esta" são elementos contextuais, envolvendo um gesto de apontar ou a intenção do falante (cf. KAPLAN, 1989), não o conteúdo conceitual das sentenças. Portanto, diz, “[...] a individuação do objeto relevante depende náo somente da informação que o pensante tenha sobre ele, mas de suas relaçôes não-conceituais e contextuais com ele" (BURGE, 2007, p. 61). Em resumo, proposiçóes e crenças de re dependem de um contexto, apartado de seu conteúdo conceitual, para serem significativas e verdadeiras, ao contrário de proposiçôes e crenças de dicto. 


\section{MCDOWELL: SENTIDOS DE RE}

Em “De resense” (1977), portanto, McDowell rejeita uma interpretação comum da semântica fregiana, de que o conteúdo assertivo de uma proposição, seu sentido, é independente da existência do objeto ao qual ela se refere, sustentando, em conjunto com Evans, sentido de re para termos e expressóes singulares. ${ }^{13}$ A tese é defendida contra a distinção de dictolde re de Burge, cuja crítica se pode formular em um argumento análogo ao de Davidson, apresentado no primeiro capítulo:

i. Somente fatores contextuais e não conceituais podem determinar o objeto de uma crença.

ii. O conteúdo (conceitual) de uma crença é separado do contexto do objeto.

iii. Por conseguinte, o conteúdo (conceitual) de uma crença (sentido) não é capaz de determinar o objeto de uma crença.

Mais uma vez, é a premissa (ii) do argumento que McDowell vai rejeitar, de sorte a evitar sua conclusão (McDOWELL, 1998b, p. 219).

De acordo com Burge, uma crença cujo conteúdo é inteiramente conceitualizado é exaurida por uma proposição linguisticamente encadeada, estando, assim, independente de elementos contextuais ou extralinguísticos capazes de determinar a atribuiçáo correta da crença ao seu objeto.

Contudo, ressalta McDowell, esse raciocínio faz uma confusão entre: (a) conceitos como meios de representação; e (b) conceitos como partes ou aspectos do conteúdo de um estado mental representacional, como uma crença (McDOWELL, 1998b, p. 218). No primeiro caso, conceitos seriam análogos ao que eles expressam, as próprias palavras. Por exemplo, as palavras que compóem a sentença "Esta xícara de café é branca" ("esta", "xícara" etc.). No segundo caso, conceitos são análogos ao que é expresso pelas palavras, ou seja, o conteúdo cognitivo de <Esta xícara de café é branca $>$.

\footnotetext{
${ }^{13} \mathrm{O}$ problema é não tanto o quanto essa interpretação de Frege é correta, mas o quanto ela se ajusta ao âmbito das questóes abordadas por McDowell. De fato, quando Frege discute o conceito de sentido (Sinn), ele parece estar mais preocupado com aspectos cognitivos (juízos ou crenças) da apreensão de uma referência fora de contextos científicos de busca pela verdade, do que propriamente em como incorporar um conteúdo extraconceitual da realidade, isto é, a relação entre mente e mundo (CARL, 1994, cap. 7).
} 
Uma vez que essa falha - separação entre conceito e contexto - é identificada, não faria mais sentido fazer uma separação entre enunciados de dictol de re baseados nela. Mais do que isso, o conteúdo conceitualizado de uma crença não se confunde com o repertório simbólico do sujeito, porém, figura objetos perceptivos como modo de apresentação (sentido de re) deles. $\mathrm{O}$ argumento de Burge, afirma McDowell, seria o mesmo que sustenta a interpretação de sentidos fregianos como sendo expressos, em uma sentença com termos singulares, quer o indivíduo exista, quer não (perspectiva independente do objeto) (McDOWELL, 1998b, p. 219).

A questão central aqui é a mesma de Mente e Mundo: uma separação entre conteúdo e contexto que somente se sustenta em um quadro cartesiano de espaço conceitual como sendo privado e subjetivo. É essa concepção que McDowell critica em Davidson, em Mente e Mundo, e, aqui, em Burge: o que emerge dela é um modelo de realismo representativo o qual postula que objetos da experiência estão diante da mente, existam ou não. Mesmo quando percebidos, eles o são de maneira indireta, "por procuração":

\begin{abstract}
Analogamente, se um objeto pensado demonstrativamente está presente à mente somente da maneira que algo poderia estar disponível ao pensamento mesmo que o objeto não existisse, o objeto está diante da mente somente por procuração. Sem uma aparentemente inescapável compulsão, é difícil crer que alguém toleraria esse modo indireto de explicar como um pensamento demonstrativo nos conecta a objetos (McDOWELL, 1998b, p. 225-226).
\end{abstract}

Por um lado, é difícil imaginar que uma crença possa ser determinada por algo que não seja parte do espaço cognitivo (lógico) do sujeito. Por outro, um pensamento singular dirige-se a algo que é independente da mente, e isso tampouco não pode ser explicado por esse ponto de vista. A recomendação, para evitar essa tensão, é "pensamentos que são tanto de re quanto parte do mundo cognitivo daquele que pensa” (McDOWELL, 1998b, p. 227).

McDowell desenvolve essa crítica em "Singular though and the extent of inner space” (1986). ${ }^{14} \mathrm{O}$ argumento sugere abandonar a concepção cartesiana presente na perspectiva dependente do objeto de Russell, retendo a ideia de contato direto com o mundo, mediante a percepção, admitindo pensamentos singulares neofregianos. A seguinte passagem expóe essa tese:

\footnotetext{
${ }^{14}$ Cf. também "Intentionality de re" (1991), a respeito de sua crítica ao representacionismo internalista de John Searle.
} 
Em um quadro completamente cartesiano, a vida interior acontece em um reino autônomo, transparente à consciência introspectiva de seu sujeito; o acesso da subjetividade ao resto do mundo se torna correspondentemente problemático [...]. Se houver proposiçóes singulares quase-russelianas sobre, digamos, objetos comuns perceptíveis, entre os conteúdos do espaço interno, entáo não poderemos mais considerar o espaço interno como um locus de configuraçóes que são independentes, não contempladas de condiçôes externas [...] Podemos tornar essa imagem vívida dizendo, em um espírito russeliano, que os próprios objetos podem figurar em pensamentos que estão entre os conteúdos da mente; no próprio Russell, formulaçóes como essas ligam-se à ideia de que proposiçóes singulares são individualizadas de acordo com a identidade de seus objetos, ao invés dos modos de apresentação deles, mas, numa abordagem fregeana, os pensamentos singulares podem acomodar tais locuçóes, firmemente distinguindo "figurar em" de ser "constituinte de", como um modo natural de insistir na dependência do objeto (McDOWELL, 1998c, p. 236-237).

O conceito figurar é importante aqui, pois não se trata de objetos existentes que são componentes das proposiçóes (nesse caso, haveria o problema dos nomes vazios), mas de objetos pensáveis, ou seja, abrangidos pelo espaço conceitual. Duas sentenças com termos singulares relativas ao mesmo objeto irão diferir em como cada um desses termos apresenta (figura) o objeto, ou seja, como diferem em sentidos fregianos.

"Uma proposição pode ser dependente do objeto [object-dependent] mesmo que sua identidade seja determinada não pelo Bedeutung, mas pelo Sinn de um termo singular usado em sua expressão" (McDOWELL, 2009, p. 173). ${ }^{15} \mathrm{O}$ objeto da referência deve, por isso, ser compreendido dentro de um contexto de racionalidade, o qual, por seu turno, não deve ser entendido como uma esfera subjetiva separada da realidade externa dos objetos (McDOWELL, 2009, p. 175).

Dessa forma, a proposta para dirimir o problema identificado em Mente e Mundo é conceber um espaço cognitivo e conceitual náo circunscrito por limites que separam o interno do externo - e, por interno, entender não

\footnotetext{
${ }^{15}$ Neste texto, vindica-se, portanto, a leitura de Evans sobre sentidos de re. "O Sinn de uma expressão referencial é o modo pelo qual o Bedeutung, o objeto referido, figura no pensamento que pode ser expresso pelo seu uso - o modo pelo qual alguém pensa o objeto ao pensá-lo em tal pensamento. Pode haver mais de uma maneira de pensar um objeto singular, mesmo que cada um desses modos de pensar pode não estar no repertório de quem pensa se o objeto não existe. Portanto, a fina granulação fregeana simplesmente não implica independência do objeto [object-independence]" (McDOWELL, 2009, p. 174).
} 
aquilo a que o sujeito tem acesso privilegiado, mas interno à esfera conceitual, ao "espaço lógico das razões". ${ }^{16}$ É o que o filósofo explicita: "Sentidos demonstrativos podem ser totalmente sentidos fregianos que, precisamente porque são parcialmente constituídos por relações reais com objetos externos, alcançam os objetos (McDOWELL, 2009, p. 175).

Isso é condizente com uma terceira definição de sentido (Sinn) dada por Frege - além das outras duas citadas anteriormente: sentido como modos de apresentação e como aquilo que, em parte, determina a referência -, de que sentido, uma sentença completa, é pensamento (FREGE, 2009, p. 137). Pensamento (Gedanke), contudo, não é um ato mental que ocorre no cérebro, mas um certo conteúdo objetivo apreendido quando se pensa. "Entendo por pensamento não o ato subjetivo de pensar, mas seu conteúdo objetivo, que pode ser propriedade comum de muitos" (FREGE, 2009, p. 137, n. 31).

Esse "conteúdo objetivo" é o próprio exercício da racionalidade que alcança o mundo e, em juízos ou asserções, esta é constrangida por ele: o que McDowell chama de empirismo mínimo. Por essa razáo, argumenta ele, em Mente e Mundo: "Se queremos identificar o reino do conceitual com o reino do pensamento, o modo correto de glosar 'conceitual' não é 'predicativo', mas 'pertencente ao reino fregeano do sentido' (2005, p. 146).

\section{ConsideraÇóes Finais}

Neste artigo, sugeri que dois argumentos de natureza epistêmicosemântica, derivados dos trabalhos de Davidson e Burge, suportam um tipo de representacionalismo cartesiano criticado por McDowell. Segundo ele, essa abordagem provocaria uma oscilação entre, de um lado, a recorrência a impressóes sensoriais ("mito do dado") como fundamentos de juízos sobre o mundo, e, de outro, uma explicaçáo coerentista que tornaria esses juízos imunes aos "atritos" da realidade.

A estratégia para evitar essa tensáo, segundo McDowell, consiste em supor que capacidades conceituais já estejam em atividade, na percepçáo. Em outras palavras, é preciso, diz, conceber a percepção como sendo conceitualmente estruturada. Essa estrutura conceitual, por seu turno,

\footnotetext{
${ }^{16}$ Esse aspecto é trabalhado por Alves (2014), que explora como essa visão cartesiana em Russell enviesou a interpretação de Frege, ao longo dos trabalhos de Burge, Kaplan e Searle.
} 
compreenderia um conteúdo proposicional que seria mais bem compreendido como sentido de re, no qual a proposição é dependente do objeto.

Todavia, como isso nos ajudaria a distinguir uma percepção genuína de um objeto da mera aparência desse objeto, em casos de ilusão ou alucinação?

$\mathrm{Na}$ epistemologia tradicional, há uma simetria epistêmica entre a experiência de perceber um objeto real e a experiência de uma ilusão. Não existem, portanto, garantias de que um sujeito acesse a realidade, pois ambas as experiências são fenomenologicamente indistinguíveis. Nada o preveniria, nesse ponto de vista, de estar em um cenário cético.

Segundo McDowell, tal imagem supóe que haja um "máximo denominador comum" entre uma situação cognitivamente boa, na qual o sujeito acessa a realidade, e outra ruim, na qual tem apenas uma ilusão (McDOWELL, 2005, p. 152, cf. 1998a, p. 386 e ss.; 1998c, p. 242; 2009, p. 230). Ao contrário, McDowell sugere uma concepção disjuntivista da aparência perceptual, na qual ou o indivíduo percebe as coisas como elas são ou não.

O disjuntivismo epistemológico de McDowell propõe que não há, nessa disjunção exclusiva, elementos epistêmicos comuns entre ambas as experiências - a de perceber corretamente o mundo e a de ser enganado pelos sentidos. Assim, em boas condiçóes, quando o sujeito percebe que " $F$ é G", ele acessa bases conclusivas para seu juízo. Mas, em más condiçóes, como diante de uma ilusão, por exemplo, ele não se daria conta de que não possui tais garantias epistêmicas.

O célebre exemplo da zebra de Fred Dretske pontua essa diferença. Quando vejo um animal que parece ser uma zebra, minhas capacidades cognitivas para dizer se é de fato uma zebra ou uma mula pintada são falíveis. Contudo, disso não segue, diz McDowell, que não tenha as condiçóes para reconhecer o animal, quando, de fato, ele é uma zebra (McDOWELL, 2009, p. 239) ${ }^{17}$.

A estratégia de McDowell não é responder ao problema cético, mas dirimir a questão, propondo a teoria de que a percepção provê uma "abertura para o mundo". Essa "abertura" deve ser entendida como um acesso direto

${ }^{17} \mathrm{O}$ disjuntivismo, em McDowell, é discutido na sexta conferência de Mente e Mundo (McDOWELL, 2005) e, anteriormente, nos artigos "Criteria, defeasibility, and knowledge" (1998a) e "Singular thought and the extent of inner space" (1998c). Para uma exposição geral e crítica ao disjuntivismo de McDowell, cf. Soteriou (2016, cap. 5). 
aos objetos e suas propriedades. Para cumprir esse projeto, conforme vimos ao longo deste artigo, foi preciso conceber um conteúdo estruturado em proposiçóes dependentes do objeto.

Proposições russelianas, as quais identificam o conceitual com o predicativo, não atendem a tais propósitos, pois pressupóem uma simetria epistêmica entre uma experiência verídica e uma alucinação, cujo desafio cético é respondido com o apelo aos dados dos sentidos - o "máximo denominador comum" entre ambas as experiências. Essa perspectiva, segundo vimos, é cartesiana, no sentido em que "internaliza" o espaço lógico das razôes.

Ao contrário, pensamentos singulares, sendo proposiçôes fregianas de re, somente são ditos genuínos quando incorporam, em um conteúdo inteiramente conceitualizado, os objetos aos quais se referem. Em casos de nomes próprios vazios, há apenas um pensamento aparente (Scheingedanken), pois não existe indivíduo denotado. Ambos os conteúdos carecem de um "máximo denominador comum" semântico, a saber, somente no primeiro caso são atribuídos valores de verdade à sentença. E é somente, por conseguinte, no caso de um pensamento singular genuíno que um juízo empírico pode ser justificado.

Segue-se disso uma concepção de assimetria epistêmica sobre o conteúdo perceptual da experiência: em boas condiçóes, o sujeito percebe com êxito objetos no seu ambiente e, assim, tem acesso a garantias conclusivas para seu juízo empírico. Em más condições (casos de alucinação ou ilusôes), as mesmas garantias não podem ser acessadas, mesmo que o sujeito não se dê conta disso. O ceticismo, dessa maneira, não é visto mais como um problema.

Há, portanto, uma dependência teórica entre as teses conceitualistas do conteúdo da experiência, pensamentos demonstrativos neofregianos e a noção disjuntivista da percepçáo (esta sustentada pelas teses anteriores), que subjaz ao projeto filosófico de McDowell.

SALATIEL, J. R. The Neo-Fregean conception of proposition in j. Mcdowell's mind and world. Trans/form/açâo, Marília, v. 43, n. 4, p. 231-254, Out./Dez., 2020. 


\begin{abstract}
Traditional epistemology deals with questions such as the justification of empirical beliefs in a Cartesian representationalistic approach, which separates concepts and experience in two different metaphysical domains. But, in this way, it is difficult to explain how perception can have a normative role in the process of justification of our knowledge about the world. The solution recommended by McDowell's Mind and World is to consider that perception entail conceptual abilities and it provides direct access to the objects of external reality. Furthermore, McDowell endorse Evan's neoFregean theory of proposition, which partly explains how the content of experience can be structured in order to meet minimal empiricism. This papers aims to analyze the consequences of McDowell's neo-Fregean semantics for the philosophical project devised in Mind and World. I argue that this connection between conceptualist theory of perception and semantics theory of de re senses support epistemological disjunctivism, which aims to evades the skeptical problem.
\end{abstract}

Keywords: Singular thought. Perception. McDowell. Frege.

\title{
REFERÊNCIAS
}

ALVES, M. A. Fregean de re thoughts. Cognitio-Estudos, v. 11, n. 1, p. 1-12, jan./ jul., 2014.

BELL, D. How Russellian was Frege? In: BEANEY, M.; RECK, E. H. (eds.). Gottlob Frege: critical assessments of leading philosophers. V. 4: Frege's philosophy of thought and language. London; New York: Routledge, 2005. p. 68-80.

BURGE, T. Belief de re. In: BURGE, T. Foundations of mind. Philosophical essays, v. 2. Oxford: Clarendon Press, 2007.

CARL, W. Frege's theory of sense and reference: its origins and scope. Cambridge, Mass.: Cambridge University Press, 1994.

CRAWFORD, S. Perceptual demonstrative thought: a property-dependence theory. Topoi: an International Review of Philosophy, p. 1-19, 2018. Disponível em: https://doi. org/10.1007/s11245-017-9537-x. Acesso em: 26 jun. 2018.

DAVIDSON, D. A coherence theory of truth and knowledge. In: LePORE, E. (ed.). Truth and interpretation: perspectives in the philosophy of Donald Davidson. Cambridge: Basil Blackwell, 1986. p. 307-319.

EVANS, G. The varieties of reference. Oxford: Oxford University Press, 1982.

FREGE, G. Sobre o sentido e a referência. In: FREGE, G. Lógica e Filosofia da Linguagem. Seleção, introdução, tradução e notas: Paulo Alcoforado. 2. ed. amp. e rev. São Paulo: Unesp, 2009. p. 129-158.

FREGE, G. Posthumous Writings. HERMES, H; KAMBARTEL, F; KAULBACH, F. (eds.). Trans.: Peter Long; Roger White. Oxford: Basil Blackwell, 1979. [Citado como PW.]

FREGE, G. Philosophical and Mathematical Correspondence. GABRIEL, G. et al (eds.). Trans.: Hans Kaal. Oxford: Basil Blackwell, 1980. [Citado como PMC.] 
GEIRSSON, H. Frege and object dependent propositions. Dialectica, v. 56, n. 3, p. 299-314, 2002.

KANT, I. Crítica da razáo pura. Col. Os Pensadores. Trad. De Valério Rohden e Udo Baldur Moosburger. São Paulo: Abril Cultural, 1980.

KAPLAN, D. Demonstratives: an essay on the semantics, logic, metaphysics, and epistemology of demonstratives and other indexicals. In: ALMOG, J.; PERRY, J. and WETTSTEIN, H. (eds.). Themes from Kaplan. New York: Oxford University Press, 1989 , p. 481-564.

McDOWELL, J. [1982]. Criteria, defeasibility, and knowledge. In: McDOWELL, J. Meaning, knowledge, and reality. Cambridge, Mass.; London, England. Harvard University Press, 1998a. p. 369-394.

McDOWELL, J. [1984]. De re senses. In: McDOWELL, J. Meaning, knowledge, and reality. Cambridge, Mass.; London, England. Harvard University Press, 1998b. p. 214227.

McDOWELL, J. [1986]. Singular thought and the extent of inner space. In:

McDOWELL, J. Meaning, knowledge, and reality. Cambridge, Mass.; London, England. Harvard University Press, 1998c. p. 228-259.

McDOWELL, J. [1991]. Intentionality de re. In: McDOWELL, J. Meaning, knowledge, and reality. Cambridge, Mass.; London, England. Harvard University Press, 1998d. p. 260-274.

McDOWELL, J. [1995]. Knowledge and the internal. In: McDOWELL, J. Meaning, knowledge, and reality. Cambridge, Mass.; London, England. Harvard University Press, 1998e. p. 395-413.

McDOWELL, J. [1994]. Mente e mundo. Tradução de João Vergílio Gallerani Cuter. Aparecida, SP: Ideias \& Letras, 2005.

McDOWELL, J. Evans's Frege. In: McDOWELL, J. The engaged intellect: philosophical essays. Cambridge; London: Harvard University Press, 2009. p. 163-185.

RUSSELL, B. [1917]. Conhecimento por familiaridade e conhecimento por descrição. In: McDOWELL, J. Misticismo e lógica; e outros ensaios. Tradução de Alberto Oliva e Luiz Alberto Cerqueira. Rio de Janeiro: Zahar, 1977. p. 215-236.

RUSSELL, B. Da denotação. [1905]. In: RUSSELL, B. Lógica e conhecimento: ensaios escolhidos. Col. Os Pensadores. 3. ed. Tradução de Pablo Rubén Mariconda. São Paulo: Nova Cultural, 1989a.

RUSSELL, B. [1918]. A Filosofia do atomismo lógico. In: RUSSELL, B. Lógica e conhecimento: ensaios escolhidos. Col. Os Pensadores. 3. ed. Tradução de Pablo Rubén Mariconda. São Paulo: Nova Cultural, 1989b.

SALATIEL, J. R. Evans sobre Scheingedanke. Griot: Revista de Filosofia, Amargosa - BA, v.19, n.2, p.71-86, jun., 2019. 
SELLARS, W. Empirismo e filosofia da mente. Tradução de Sofia Inês Albornoz Stein. Petrópolis, RJ: Vozes, 2008.

SOTERIOU, M. Disjuntivism. London, New York: Routledge, 2016.

QUINE, W. V. O. Referência e modalidade. In: QUINE, W. V. De um ponto de vista lógico. Trad. Antonio Ianni Segatto. São Paulo: UNESP, 2011. p. 195-233.

WHITEHEAD, A. N.; RUSSELL, B. Principia Mathematica. Vol. 1. Cambridge: Cambridge University Press, 1910. 
SALATIEL, J. R. 